\title{
Towards Smart and Sustainable Communities
}

\section{Marta Bottero $^{1, \mathrm{a}}$, Valentina Ferretti ${ }^{1, \mathrm{~b}}$, Giulio Mondini ${ }^{1, \mathrm{c}}$}

${ }^{1}$ Politecnico di Torino, Department of Regional and Urban Studies and Planning, Viale Mattioli 39, 10125, Torino, Italy

amarta.bottero@polito.it, 'valentina.ferretti@polito.it, cgiulio.mondini@polito.it

Keywords: Sustainable Development, Indicators, Future Cities, Environmental Debt/Loan, Evaluation.

\begin{abstract}
The present paper aims at developing some reflections about the evolution of the sustainable development paradigm, from the triple-bottom line approach, to the concept of smart city and to the idea of sustainable communities. The paper also explores the main features of the future of cities, which will be based on the notion of social capital.
\end{abstract}

\section{Introduction}

Sustainable development has been defined as the "development that meets the needs of the present without compromising the ability of future generations to meet their own needs" [1]. Whereas the aforementioned definition presented a two-pillars model reflecting environment and development concerns, a later model has been proposed and it is based on the so-called "triple bottom line" considering to separate development issues into environmental, social and economic factors. Later on, more inclusive approaches have been taken into account, which add new dimensions to the model, such as the political-institutional aspects, the cultural factors and the technological elements [2].

Recently, the concept of sustainability has been broaden in order to consider other relevant issues. In this sense, the latest strategies of the European Communities in the context of regional development (Europe 2020) focus on three main areas:

- smart growth: this area is related to knowledge, innovation, education and digital society;

- sustainable growth: this line refers to the development of a more efficient production from the point of view of natural resources' use;

- inclusive growth: this part concerns the creation of job and skills, the war against poverty and the increase in life quality.

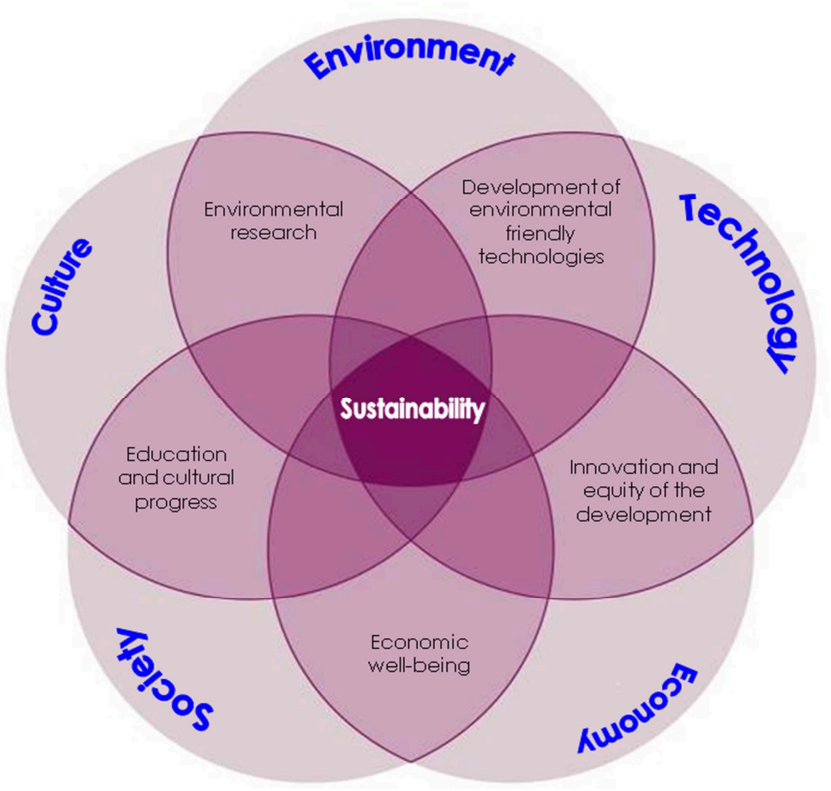

Figure 1 The scheme of the lotus flower for representing the concept of sustainability (source: [2]). 


\section{The concept of smart city}

With specific reference to the theme of smart city, it is possible to notice that the concept is assuming more and more importance in the policy makers agenda during the last years.

In fact, the problems related to cities will be crucial in the next future. In this sense, it is possible to highlight that in $2010,50 \%$ of the world's population lived in urban areas and this figure is forecast to rise to $75 \%$ by 2050 [3]. Due to this increase in urban population, governments are required to figure out how to create future spaces for the citizens. In this sense, it is necessary to think about the future quality of life in cities.

The smart cities can be defined as those cities that utilize information and communication technologies (ICT) with the aim to increase the life quality of their inhabitants while providing sustainable development. The basic idea under the concept of smart city is that through the implementation of information and communication technologies into municipal services, cities are able to be more intelligent in their resources management and can create new business opportunities and a research hub for attracting companies, entrepreneurs and research institutes [4].

According to the scientific literature [5], 6 are the main axis for the creation of a smart city; these axis can be described as follows: 1) smart governance, 2) smart economy, 3) smart people, 4) smart living, 5) smart environment, 6) smart mobility. Moreover, cities should base their Smart City models on three main pillars: infrastructure, human capital and information (Figure 2).

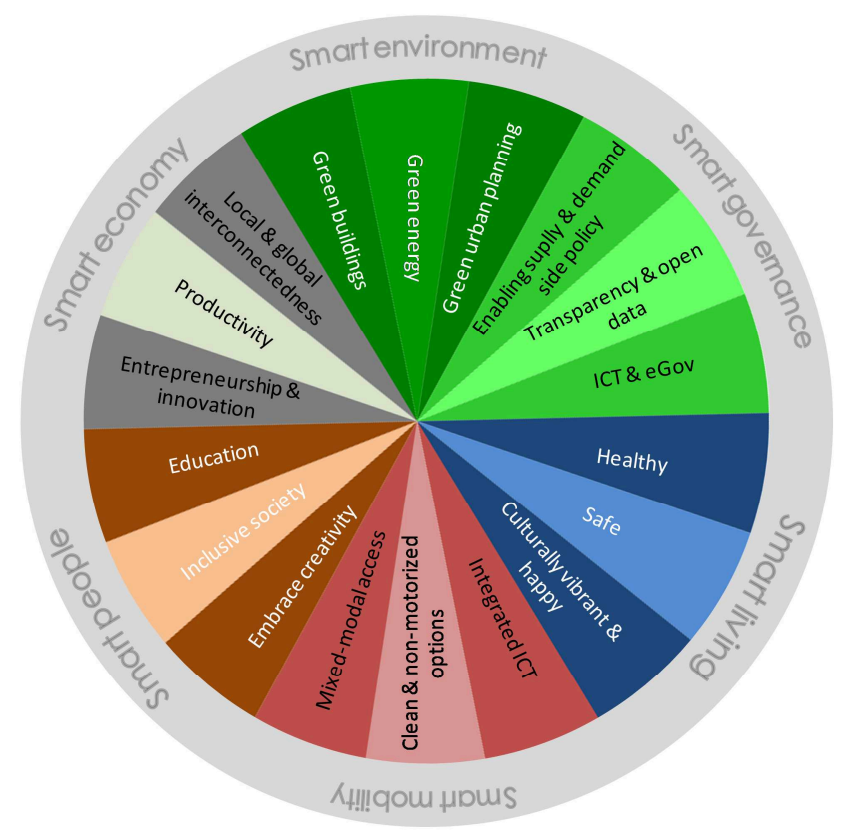

Figure 2 The concept of smart city represented by the "Smart City Wheel" (elaboration from [6]).

Recently some authors put in evidence the fuzzy nature of the concept of smart city. According to these authors, the smart city can be summarized in the following elements [7, 8]:

1. Use of networked infrastructure (e.g., business services, housing, leisure and lifestyle services, and ICTs, including mobile and fixed phones, satellite TVs, computer networks, e-commerce, internet services, etc.) to improve economic and political efficiency and enable social, cultural and urban development;

2. Emphasis on business-led urban development;

3. Strong focus on the aim to achieve the social inclusion of various urban residents in public services., with specific reference to public participation, e-democracy and e-governance [9];

4. Stress on the crucial role of high-tech and creative industries in long-run urban growth, following the ideas of Richard Florida [10];

5. Deep attention to the role of social and relational capital in urban development.

6. Social and environmental sustainability as a major strategic component of smart cities. 


\section{The concept of sustainable communities}

The progress in addressing key sustainability challenges, such as climate change, seems to come largely from cities and towns, where most of the global population actually lives.

Communities are characterized by natural, physical, economic, human, social, and culture attributes, which if properly utilized can be an effective capital basis for mobilizing community actions. Local governments and therefore local communities are increasingly being recognized for their potential role in dealing with environmental issues. This is due to the fact that local action, strongly entrenched in community participation, is fundamental in confronting local, regional and global sustainability challenges [11].

Communities that are environmentally sustainable, socially equitable, and economic viable are suitable positioned to respond to changes in the natural and built environment. They can be laboratories for policy invention, providing the models for national level policies and programs. Due to this reasons, interest in sustainable communities has exploded in recent years $[12,13]$. But what is a sustainable community? According to Rosedal [12], it can be defined as one that "uses its resources to meet current needs while ensuring that adequate resources are available for future generations. It seeks a better quality of life for all its residents while maintaining nature's ability to function over time by minimizing waste, preventing pollution, promoting efficiency and developing local resources to revitalize the local economy. Decision-making in a sustainable community stems from a rich civic life and shared information among community members. A sustainable community resembles a living system in which human, natural and economic elements are interdependent and draw strength from each other" ([12], p. 27). A sustainable community thus not only sustains the quality of our lives, but also improves it.

Sustainable Community Development (SCD) aims at integrating economic, social and environmental objectives in community development, based on a consideration of the relationship between economic factors and other community elements such as housing, education, the natural environment, health, accessibility and the arts. SCD has emerged as a compelling alternative to conventional approaches to development: a participatory, holistic and inclusive process that leads to positive, concrete changes in communities by creating employment, reducing poverty, restoring the health of the natural environment, stabilizing local economies, and increasing community control [14].

As already mentioned in section 1, originating from the World Commission on Environment and Development's definition of sustainable development, there have been several efforts to describe sustainable community development in terms of three types of capital: economic, social and ecological capital (e.g. [15]). Rosedal [12] proposed instead an approach based on six smaller, more nuanced forms of capital: natural, physical, economic, human, social and cultural capital. These six forms of capital are the backbone of the Community Capital Framework (Figure 3), which seeks balance between all the capital.

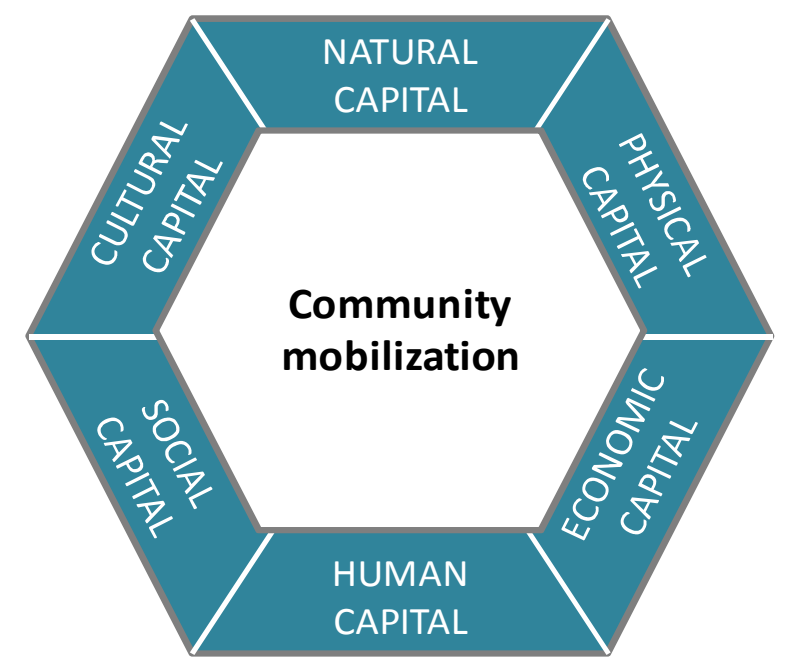

Figure 3 The framework for Sustainable Community Development (source: elaboration from [12]). 
A critical element in the framework refers to community mobilization. Applying the concept of sustainable development to communities implies mobilizing citizens and their governments to strengthen all forms of community capital. Elements of this framework include minimizing consumption of essential natural capital and improving physical capital, which in turn require the more efficient use of urban space. This sustainability framework also includes strengthening economic capital, increasing human capital, multiplying social capital and enhancing cultural capital. Community mobilization is necessary to coordinate, balance and catalyze community capital [12].

In particular, the Community Capital Framework has been designed from the following principles [12]:

1. Communities need all six forms of capital to achieve well-being and sustainability. No single capital is sufficient in creating or supporting sustainability.

2. It is important to understand your community's capital, including strengths and weaknesses.

3. Capital interact with each other; changes in one form of capital may generate positive or negative changes in other forms of capital.

From an operational point of view, different conceptual building blocks can be identified for sustainable communities, as summarised in Table 1.

Table 1 Key sustainable communities building blocks (source: [12])

\begin{tabular}{|l|}
\hline 1. Cultivating greener, food- secured communities \\
\hline 2. Water and sewage \\
\hline 3. Waste reduction and recycling \\
\hline 4. Energy efficiency and renewable \\
\hline 5. Transportation planning and traffic management \\
\hline 6. Land use, urban form and community design \\
\hline 7. Housing and community development \\
\hline 8. Green building \\
\hline 9. Community economic development \\
\hline 10. Climate change \\
\hline 11. Communities integrating sustainability \\
\hline
\end{tabular}

The sustainable community concept thus calls for interdisciplinary and crosscutting approaches to problem framing and policy response, by encouraging environmentalists to think carefully about the social and economic needs of a community; developers to understand the rudiments of ecosystem management; civic leaders to recognize the interdependence of communities in both ecological and economic terms; and ordinary citizens to draw connections between civic engagement and quality of life [13].

\section{Conclusions}

Following from the previous considerations, it becomes interesting to think about the new directions that seem to arise from the evolution of the sustainability paradigm and in particular from the upset of the traditional approach adopted so far for studying sustainability.

According to this approach, the interest focuses on the possibility of transferring to the future generations the economic, social and natural capital. According instead to the innovative approach, the capital is taken as a loan from the future generations and the attention focuses on the modalities according to which to return it. If we recall the Ancient American Indian proverb "treat the Earth well: it was not given to you by your parents, it was loaned to you by your children", it becomes clear that it refers to a loan process, where the present generation is the one that receives the loan and the next generation is the one that gives it. If we thus assume that we have not inherited the Earth from our ancestors, but that we borrow it from our children, we one day should give it back to them and account for what we have done to it. This means that we should try to remediate for the damages that we have caused and compensate for those damages that we cannot remediate [16]. 
This last interpretation of sustainability as a loan from the future seems to open new interesting directions and research areas where the estimate and project appraisal discipline plays a very crucial role.

\section{Acknowledgments}

The paper is the result of the joint work of the three authors. Despite the overall responsibility being equally shared, Marta Bottero is responsible for "The concept of smart city" paragraph, Valentina Ferretti is responsible for "The concept of sustainable communities" paragraph and Giulio Mondini is responsible for the introduction. The abstract and the conclusions are the result of the joint work of the three authors.

\section{References}

[1] World Commission: Our common future. Oxford University Press, Oxford (1988)

[2] G. Mondini: Valutazione e complessità, in: Valutazione e sostenibilità: piani, programmi, progetti, edited by M. Bottero, G. Mondini, Celid, Torino (2009), pp. 15-18

[3] UN: World urbanization prospects: the 2007 revision population database, United Nations (2008)

[4] L.G. Anthopoulos, A. Vakali: Urban planning and smart cities: interrelations and reciprocities, in: FIA 2012, LNCS 7281, edited by F. Álvarez et al. (2012), pp. 178-189

[5] Centre for Regional Science, Vienna UT: Smart cities. Ranking of European medium-sized cities (2007). Information on http://www.smart-cities.eu/download/smart_cities_final_report.pdf/

[6] B. Coen: The smart city wheel (2013). Information on http://www.boydcohen.com/smartcities .html/

[7] A. Caragliu, C. Del Bo, P. Nijkamp: Smart cities in Europe, 3rd Central European Conference in Regional Science - CERS (2009), pp. 45-59

[8] R. G. Holland: Will the real smart city please stand up?, City, 12 (3) (2008), pp. 303- 320

[9] A. Coe, G. Paquet, J. Roy: E-governance and smart communities: a social learning challenge, Social Science Computer Review, 19 (1) (2008), pp. 80-93

[10]R. L. Florida: The rise of the creative class: and how it's transforming work, leisure, community and everyday life, Basic Books, New York (2002)

[11]K. O. Zimmermann: Foreword, in: Toward sustainable communities: solutions for citizens and their governments, edited by M. Rosedal, New Society Publishers, Canada (2012)

[12] M. Rosedal: Toward sustainable communities: solutions for citizens and their governments. New Society Publishers, Canada (2012)

[13] L. C. Hempel: Conceptual and analytical challenges in building sustainable communities, in: Toward sustainable communities. Transition and transformation in environmental policy, edited by D.A. Mazmaniam., M.E. Kraft, Massachusetts Institute of Technology (2009), pp. 33-62

[14] Simon Fraser University: Sustainable Community Development (2014), Information on http://www.sfu.ca/cscd.html/

[15] D. Rainey, K. Robinson, I. Allen, L. Christy: Essential forms of capital for sustainable community development. American Journal of Agricultural Economics. 85(3) (2003), pp. 708-715

[16] M. Bottero, V. Ferretti, G. Mondini: From the environmental debt to the environmental loan: trends and future challenges for intergenerational discounting, Environment, Development And Sustainability 15 (2013), pp. 1623-1644 